\title{
Prescriptive Authority and Nursing: a comparative analysis of Brazil and Canada
}

\author{
Maria Lígia dos Reis Bellaguarda ${ }^{1}$ \\ Sioban Nelson ${ }^{2}$ \\ Maria Itayra Padilha ${ }^{3}$ \\ Jaime Alonso Caravaca-Morera ${ }^{4}$
}

\begin{abstract}
Objective: to analyse the differences between medication prescriptions by nurses in Brazil and Ontario, Canada. Methods: a comparative study between two different scenarios; this comparison was not performed between the two countries because Canada does not standardize this practice, which is legally established and is considered as an advanced professional knowledge area in Brazil. Results: prescription is a professional position to be occupied by nurses. However, there is tension surrounding this practice because it is perceived as a threat to privileges or traditions of other health professionals. Prescibing medication by nurses in Brazil and Ontario follows current legislation and training proccess in each context. Conclusions: there are some challenges to be overcome in ensuring the visibility and consolidation of the practice by nurses in these realities: guarantee of professional competence, credibility, acceptability, and the respectability of clientele in your professional scope by other health professionals.
\end{abstract}

Descriptors: Nursing; Medication Systems; Prescription Drugs; Health Councils.

\footnotetext{
1 PhD, RN, Associação Brasileira de Enfermagem, Florianópolis, SC, Brazil. Scholarship holder from Coordenação de Aperfeiçoamento de Pessoal de Nível Superior (CAPES), Brazil.

2 PhD, Adjunct Professor, Lawrence S. Bloomberg Faculty of Nursing, University of Toronto, Toronto, ON, Canada.

${ }^{3} \mathrm{PhD}$, Adjunct Professor, Departamento de Enfermagem, Universidade Federal de Santa Catarina, Florianópolis, SC, Brazil.

${ }^{4}$ Doctoral student, Universidade Federal de Santa Catarina, Florianópolis, SC, Brazil. Adjunct Professor, Escuela de Enfermería, Universidad de Costa Rica, San José, SJ, Costa Rica.
}

Corresponding Author:

Maria Lígia dos Reis Bellaguarda

Associação Brasileira de Enfermagem

Rua João Meirelles, 884/101/bl.F

Bairro: Abraão

CEP: 88085-201, Florianópolis, SC, Brasil

E-mail: bellaguardaml@gmail.com
Copyright () 2015 Revista Latino-Americana de Enfermagem This is an Open Access article distributed under the terms of the Creative Commons Attribution Non-Commercial License (CC BY-NC).

This license lets others distribute, remix, tweak, and build upon your work non-commercially, and although their new works must also acknowledge you and be non-commercial, they don't have to license their derivative works on the same terms. 


\section{Introduction}

This paper analyse the practice of medication prescription by nurses in Brazil and in Canada. However, because of the distinct nursing practices and norms among the Canadian provinces, the chosen province for this work was that of Ontario.

Today, there is a pressing need for a comprehensive dialogue between nurses and other health professionals regarding the scope and limits of their practices in healthcare services. Moreover, these negotiations should be in accordance with professional policies and within the scope of social policies(1).

Medication prescription, as well as clinical diagnoses of patients' diseases, had been considered a prerogative of the medical profession for centuries. However, throughout the twentieth century, issues such as medication prescription by nurses at different levels of complexity and scope began to be discussed worldwide(2).

Throughout the history of their profession, nurses have acquired the expertise, the advanced knowledge and the legal practice to prescribe medication. New technologies require nursing professionals to have their own knowledge and skills to combine with the interdisciplinary healthcare practices and thus nursing has become a more specialized activity.

There are disagreements between different groups of health professionals in the understanding of the professional scope of the practice, which is sometimes seen as an inclusive and necessary job and sometimes as something that appropriates its power from other professionals. These disagreements come about where the work process takes place such as in law courts and in publications in the media(2-4).

In this sense, the objective of this study was to analyse the differences between medication prescriptions by nurses in Brazil and Ontario, Canada;. It is important to investigate the practice of medication prescription by nurses in both these countries, given that discussions on this topic occur worldwide. Thus, this is a comparative study, which takes advantage of knowing the same focus of a particular practice in different situations. It also grants value to the contexts being investigated, creates a basis of discussion, recognizes effective practices, and helps us to critically think and better understand these practices, given that comparative studies bring about the globalization of social policies.

\section{Methods}

This article features as a comparative study of the prescription medications by nurses in Brazil and Ontario, Canada. The option to develop this study is due to be controversial among health professionals in both realities, for the interest of the discussion concerning the laws on this issue in the countries of choice. Yet, in Toronto at the time of developing this article (2013) was debating the Bill 179 for prescribing of medication by nurses. As study of sources were used professional laws of both countries, as well as the documents of the professional nursing associations of Brazil and Canada, in addition to other legal documents. The critical analysis was also based on scientific articles related to the analyzed subject.

This comparative study assigns value to the realities under study; the discussion provides the recognition of effective practices; allows the understanding and critical thinking and magnifies the globalization of social policies. In Brazil, all nurses are qualified to prescribe medication as long as they are included in national health plans for some specific and chronic diseases such as diabetes and hypertension, or communicable diseases such as tuberculosis and leprosy. However, in Toronto, Canada, this practice requires more specific skills and training to accredit nurses to diagnose and consequently prescribe medication. In the contexts studied, access to the entire health system is through primary care and has government support. The discussions and comparisons followed the health policy contexts of prescription medications by nurses in both contexts and publicized discussions in the media on the subject in both countries.

Furthermore, there is a reflection on the similarities and differences between drug prescribing practices by nurses in Brazil and Ontario, Canada, there are expectations for a cooperative, collaborative, and health integrated practice.

\section{Results}

\section{Medication prescription by nurses: In Brazil}

The legislation for the nursing profession in Brazil has a federal scope, and thus it is in accordance with the standards established by the Brazilian constitution. Therefore, the Law for Professional Nursing Practice $\mathrm{n}^{\circ} 7498$, issued on June $25^{\text {th }} 1986$, must be complied 
with throughout the entire national territory by its professional members and, within that outline, by the whole society who benefits from the activities carried out in this profession.

This law regulates the exercise of professional nursing in Brazil and implicitly establishes the legality of the activities that are particular to nursing professionals. This is a regulatory provision "on the prescription of medicines by nurses, as members of the healthcare team, when previously established in public health programs and in a routine approved by a health institution." Federal Council for Nursing in Brazil (Cofen). Within the scope of the Cofen, other regulations have been instituted in order to extend, secure, and facilitate the interpretation of the law regarding the practice of medication prescription by nurses in Brazil.

In spite of medication prescription by nurses being established in law, the nursing practice has historically followed the rules of subordination to physicians and surgeons, and to the power of the State. Furthermore, within this scope, the understanding on the part of the nurses regarding medication prescription sometimes presents itself as a conflicting issue. On one hand there is the legal definition and on the other hand there is the difficulty for nurses to take over a position with autonomous characteristics.

Nursing consultation, drug prescription, and test ordering has emerged from the activities within the primary healthcare programs since 1986 . The practice of medication prescription by nurses in Brazil was started in 1990 with the implementation of the regulations of the Unified Health System (SUS) in Brazil, which was created by the Brazilian Federal Constitution in 1988. There has been real expansion and applicability of this practice by nurses since 2006 with the development of the Family Health Strategy (ESF) in Brazil, which was a model in which the family is the object of attention from within the environment where they live(5).

Medication prescription by nurses in Brazil follows the model described by the International Council of Nurses (ICN) as a protocol group. This therefore refers to predetermined protocols that specify what drugs can be prescribed by nurses. In Brazil, these protocols are defined by the Policy for Primary Health Care which was established by the Ministerial Order n.648/2006 (which was revoked and the Ministerial Order no. $2488 / 2011$ is currently enforce) and/or by protocols arranged and approved in health institutions. In Brazil, medication prescription by health professionals who have university level training has become ever more widespread since the National Policy on Integrative and Complementary Practices in the Unified Health System (PNPIC-SUS) was established in 2006. In accordance with the recommendations by the World Health Organization, that policy incorporates the traditional practices and the use of medicinal plants in health care, enhancing the business sector with nonprofessional cultural practices( ${ }^{(6)}$.

In Brazil, nurses have the autonomy and legality not only to prescribe pre-established allopathic drugs but also to prescribe (and even specify the aspects of manipulation and usage of) medicinal plants, either dry or fresh, in the form of teas to be used in clinical treatments. However, the prescription of herbal medicines by nurses with extra training and credentials also follows the regulations set by the country's Ministry of Health and it may be performed only if it is in accordance with the therapeutic protocol defined in the Municipal Health Secretariats as well as in the clinics $^{(7)}$.

As part of primary health care, nurses in Brazil render previously appointed nursing consultations throughout the health system and attend to specific areas, such as women's health, adults' and elderly health, children's and adolescents' health, and groups related to specific chronic diseases such as diabetes, hypertension and others. The health service users firstly receive nursing consultation and are subsequently referred to a doctor when it is necessary.

Nursing care is recommended and medications are prescribed when necessary, from nursing consultations at primary healthcare units, as well as in home visits ${ }^{(4)}$. There are three conducts to be observed for medication prescription by nurses in Brazil. First, medication prescribed by nurses is always preceded by the nursing assessment and diagnosis; second, the drugs must come from an approved national protocol; and third, no dispensing of drugs is allowed. In this scenario, there are other controversies regarding drug dispensation because there are not enough pharmacists to attend to all the pharmacy sectors of the primary healthcare units. Thus, nurses or nursing technicians often perform drug dispensation to fulfil the needs of the community. And consequently, it becomes more difficult for the government to deploy the right number of professionals to perform the legal and social services in health care. 
Nursing assessment, diagnosis and prescription are acknowledged and accepted by the people who are undergoing treatment in primary health in Brazil. However, outside of primary health care, most people do not acknowledge the nursing professional as a professional who is able to give consultations, prescribe medication and order tests; in people's minds this is still a strictly medical practice.

\section{Medication prescription by nurses: In Ontario, Canada}

In Canada there is a universal health insurance program called Medicare, which was established in law initially in 1957 and revised in 1966 and 1984. It holds a fund, which is shared between the federal government, the provinces and the territories and is based on the premise that health is a social asset. It includes the principles of public administration, comprehensiveness, universality, portability and accessibility, whose responsibility is shared, but assumed to a greater extent by the provinces and territories in which it resides. From this perspective, there is universal coverage of all Canadian citizens and permanent residents ${ }^{(8)}$.

In the province of Ontario there is the Ontario Health Insurance Plan (OHIP), which covers the costs of services rendered to insured Ontario residents, in hospitals and health centers and health care professionals $^{(8)}$.

Public Funded Medicare covers public health, primary health care and acute care in hospitals. Public health refers to health policies, epidemiology, prevention, and laboratory tests, following educational policies and other social policies. Primary health care includes the Family Practice teams, nurse-led primary care team (nurse practitioners) as well as hospital care and attention to the community where intervention and attention to chronic diseases is held in clinics.

The law for the integration of the health system, Local Health System Integration Act (LHSIA), established regulations to improve access to health services, including community health centers, community support services, manors and mental health facilities ${ }^{(8)}$.

Since 1947, the health insurance system has been evolving Canadian health care to the current model of care, especially with the promulgation of the Canada Health Act in 1984. This law was created from a report which identified threats to accessibility of universal health care $^{(9)}$.
In the late 1990 s and early 2000s, there was a movement within the health area and the Canadian government to reorganize a new healthcare model for the population. This resulted in the public health care reform, where national efforts prioritized health promotion, equal user access to services, and the work among the different health professionals to ensure the quality of health care ${ }^{(9-10)}$. During that time, the Canadian Government's interest in nurses' activities in primary healthcare increased. According to these authors, this is characterized as the growing role of these nurses in the Canadian primary healthcare practice.

And thus, the role of nurse practitioners in Ontario emerged, promoting the work and expanding the professional scope of nurses in rural and remote areas of the province. University programs for more extensive training of nurses were established; however, it was accomplished in 1994. Health actions were needed in the interior where there was a shortage of physicians and surgeons ${ }^{(11)}$.

The practices to be performed by the various health professions are defined in a regulatory structure, Act 1991, which comprehends the activities of all professionals in this field of knowledge(12).

The specificity of each profession is directed, disciplined and supervised by professional councils. The College of Nurses of Ontario ( $\mathrm{CNO}$ ) governs the discipline and supervision of nursing services across the entire province. Act 1991 defines the activities of nursing professionals and establishes the legality of the Nurse in its 8th Controlled Act, which guarantees prescribing, dispensing, selling, compounding of drugs as defined in the Drug and Pharmacies Regulation Act, or supervising the part of a pharmacy where such drugs are kept.

In Ontario there are three categories within the profession of Nursing; namely, the Nurse Practitioners, the Registered Nurses, and the Practical Nurses. The difference between these three categories is in their professional training. Nurse Practitioners are Registered Nurses who have a university education of four years plus an additional Masters level qualification and have passed the qualifying exam to be appointed as a Nurse Practitioner. They are therefore able to prescribe medications, give diagnoses, admit and discharge patients, and also perform other activities. Registered Nurses have university education of four years. In the case of Practical Nurses, the length of time for their training is generally of two years. 
Registered Nurses and Practical Nurses do not prescribe medication.

During the 2000s, discussions were intensified in order to clarify and characterize the role of Nurse Practitioners in the Canadian health system. The leaders in the nursing field and Health Canada funded the study and review of the regulatory role of Nurse Practitioners. The aim of that study and review was to increase people's access to health, safety and other public interests and provide consistency and mobility to the work force to strengthen the health system in Canada(13). Therefore, Nurse Practitioners are defined as registered nurses with additional educational preparation and experience who possess and demonstrate the competencies to autonomously diagnose, order and interpret diagnostic tests, prescribe pharmaceuticals, and perform specific procedures within their legislated scope of practice ${ }^{(14)}$.

In relation to medication prescription, the College of Nurses of Ontario ( $\mathrm{CNO}$ ) has an important role in overseeing this activity to determine the indications standard (Standard Statement) that regulate the requirements for nurses regarding assessment, planning, implementation and the evaluation (CNO 2008). In 2003 the College of Nurses published a document with important considerations for the inclusion of nurse practitioners as a more autonomous class in hospital work and comprehensive health care coverage, medication prescription regulations, interprofessional collaboration and approval of Bill 179. This indicates the expansion of the nurse practitioners' professional scope of practice.

Medication prescription by Nurse Practitioners in Ontario follows the model of the independent, autonomous, or substitute prescriber, who is supported by the International Council of Nurses-ICN(15). In this model, the healthcare professional who prescribes medication is responsible for the entire process of consultation/patient evaluation based on the differential diagnosis and indicates the corresponding treatment and medications through a prescription.

There have been changes in Canada's health system which favored the development of the work of nurses who worked in primary health care ${ }^{(12)}$. Medication prescription by nurses in Ontario is performed in all the fields of nursing practice. In hospitals, a nurse practitioner has, according to patient distribution or internal regulatory mechanisms of healthcare institutions, a group of patients under his/her responsibility and the whole process of diagnostic investigation and treatment is defined by this professional.

The process of patient care follows the search for a primary health care service. After the consultation, the patient is referred either to a specialist or to a hospital, according to the complexity and the need noted by the family doctor or multidisciplinary healthcare workers. The care given by nurses is performed mainly within the primary team in hospitals and in the community healthcare in clinics.

The interprofessional boundaries in the health care system in Ontario are based on interprofessional communication and collaboration. Thus, in Ontario the practice of nursing is acknowledged as a complementary action from another health professional and not as practical support(16). Bill no. 179/2009 enlarges the autonomy of Nurse Practitioners regarding medication prescription, extra legal authority, and admission and discharging of patients within specific areas of health care and professional knowledge ${ }^{(17)}$.

In Ontario, service users usually have difficulty to distinguish the work of doctors from that of nurse practitioners since the activities performed and the powers and capacity to provide health care are the same within the professional realm. However, the training, the foci of care and coverage are different between such healthcare professionals. Down below we present a figure that highlight the main differences between both countries.

\begin{tabular}{|l|l|l|}
\hline & \multicolumn{1}{|c|}{ Brazil } & \multicolumn{1}{|c|}{ Ontario/Canada } \\
\hline Scope of legislation & National/Federal Legislation & State Legislation of the province of Ontario \\
\hline Entity of Control & Federal Council for Nursing (COFEN) & The College of Nurses of Ontario (CNO) \\
\hline Autonomy & $\begin{array}{l}\text { Limited autonomy in prescribing allopathic drugs but } \\
\text { significant autonomy and legality in prescribing medicinal } \\
\text { plants }\end{array}$ & $\begin{array}{l}\text { Nurse Practitioners follow a mode of the independent, } \\
\text { autonomous or substitute prescriber supported by the } \\
\text { International Council of Nurses }\end{array}$ \\
\hline Regulatory Structure & $\begin{array}{l}\text { The protocols delineate which type of medication could be } \\
\text { prescribe and in which scenario, that protocol is defined by } \\
\text { the Policy for Primary Health Care }\end{array}$ & $\begin{array}{l}\text { The Regulatory Structure guarantees prescribing, dispensing, } \\
\text { selling, compounding of drugs }\end{array}$ \\
\hline Settings of activities & Primary Health Care & Acute and Community Health Care environments \\
\hline
\end{tabular}

Figure 1 - Comparison of nursing prescription between Brazil and Ontario/Canada. 


\section{Discussion}

Worldwide nurse prescribing has grown significantly over the last decade, primarily due to the efforts of key stakeholders and substantial legislative and policy reforms that have encouraged and supported nurses to take on prescribing roles in both acute and community settings. Consequently, the nursing role in medicines management is currently undergoing a major transformation.

This comparative study shows that there is a similarity in the healthcare systems of the two situations studied considering that the comprehensiveness and accessibility guidelines are common in both Brazil's and Ontario's healthcare systems. And while they provide comprehensive health care, which is understood as one that extends to all levels of care, they also indicate the bases to serve patients. The population's access to quality health services rely heavily on clear public policies which are targeted and effected to this perspective, the commitment of health workers and their ability to decrease professional boundaries, and the real participation of society in conducting the creation of goals to be achieved within the scope of public policy.

In both health systems referred to in this work, the public health authorities are concerned about focusing on strategies to increase the population's access to meet their health needs. In Brazil and in Ontario accessibility is made through the comprehensiveness that these health care systems offer, the way health care is distributed and how it is provided to individuals, which happens through primary health care in these two countries.

Thus, it can be said that access refers to the healthcare services and opportunities available to people. This is therefore directly related to the quantity/distribution and competence/specificity of the workers who make up the workforce in health.

Because health services are congested by excess demand and due to the current distribution of healthcare professionals in certain regions of the two countries in question, there are professional-patient and professional-professional tensions between comprehensiveness and accessibility.

Despite having similar health guidelines, Brazil and Ontario show differences in the structure of the profession and in the training of nurses, in the prescription models and in the opportunities for development of the activity of medication prescription by nurses. Thus, these distinctions influence on how this practice has been accomplished and understood in these contexts.

The structure of the nursing profession in Brazil views the nurse as a professional who is responsible for the other members of the nursing staff and, in this perspective, one who has a generalist higher education. In Ontario, nurses are a group of professionals who have distinct scopes within the same professional class. Nurses in Ontario have a more specific training, which defines the scope of their autonomy in the practice. Thus the training nurses acquire establishes the autonomy they have in their health practices and the relationship with patients and other health professionals. Training and preparation of nurses influence on the interprofessional relationships and between nurses and patients and that leads to differences in the prescription model.

Independent medication prescription by nurses, as is the case in Ontario, stems from complex professional training. It is a founded and well-defined practice that expanded after Bill 179(8). This context brings about a health practice of complementarity with other health professionals.

The prescriptions that follow protocols, as is the case in Brazil, will meet the expectations of the existing training for nurses in the country. The expansion for independent models requires different training strategies in order to better train nursing professionals. Thus, in both these countries the prescription of medicines by nurses is directly proportional to the extension of their professional training.

The spaces in which the activity of medication prescription is performed by nurses are the same, i.e., both in primary health care and in hospitals. In Brazil, medication prescription by nurses occurs mainly in primary care because of the country's SUS. However, there are difficulties for it to become commom practice in the hospital context. Medication prescription by nurses is promoted by the Family Health Strategy within Brazil's health system but adherence to this strategy does not extend to hospital routines(7). Meanwhile, in Ontario this practice is increasingly evident in primary care and hospital settings, because of the expansion of activities established in Bill 179 regarding the prescription, admission and discharge of patients by nurse practitioners.

It is also important to report that, although it happens only incidentally, the inclusion of herbal medicines in prescriptions by nurses in primary 
health care is a breakthrough in drug prescriptions among healthcare professionals in Brazil. This practice exploits the richness of the local flora, promotes humane care and comprehensive health. It contributes to resolving the patients' health problems and increases access to previously restricted practices and also to the sustainable development of communities. Moreover, it encourages and promotes responsible involvement and social participation(18). The use of medicinal plants and herbal prescriptions in nursing indicates new areas of study and practice for health professionals and also approaches nurses and individuals in the decisions for their treatment. The educational action arising from this activity is also fundamental, and nurses have a direct and continuous relationship with the health service users $^{(19)}$. Thus allopathic and herbal therapies in medication prescriptions are combined in order to provide comprehensiveness in health care.

From this perspective, considerations on the prescription of medicines by nurses involves a clear understanding of why the nurse is prescribing and, within this context, the specifics of the training this professional receives, the coverage area of their professional practice and the relationship of this activity with other healthcare professions.

Nurses are autonomous professionals and, in the scope of such autonomy, there is the relativization of this practic. A nurse is a member of a team and, as such, a nurse does not work and does not decide by him/herself.

Within this context, when considering why nurses prescribe medication, people think of access and solution to the health problems service users have. Thus, nurses prescribe medication because they are trained regarding the required professional expertise and pertinent legal matters. Moreover, it also helps to resolve the issues that certain regions, both in Brazil and in Ontario, have in relation to deployment of health professionals. Such issues can hinder the development of integrated and continuous health practices. Within this scope, it is essential that interprofessional boundaries be clearly established in order to avoid disruptions in the comprehensiveness of health care to individuals and families. Therefore medication prescription by nurses promotes the development and improvement of professional communication and also the communication between nurses and patients. Medication prescription by nurses is also considered a resource for all the healthcare staff since it decreases and distributes excess work among healthcare professionals and also expands patients' access to health.

Medication prescription by nurses in Brazil and in Ontario requires constant planning, support, and debating in the regulatory and professional bodies in order to contribute for the comprehensiveness and accessibility of health services for the population.

Medication prescription by nurses is a legal professional practice of advanced nature which requires not only complex knowledge but also the professional's own belief of his/her competence. The visibility and understanding of society that other health professionals, and not only doctors, can also prescribe will favor further access to health and other professionals who can solve people's health problems conjunctively, to consolidate the commitment and focus of their work with people.

The controversy regarding medication prescription by nurses is a reality to be discussed, given that legislation alone does not guarantee professionalism and competence of nurses for this practice. Whether by the prescription protocol models or by the independent models, nurses are responsible for sharing efforts to ensure appropriate and qualified assistance, free of risks to individuals, families, and communities and also for developing their practice through the integration of their actions with other health professionals.

\section{Conclusion}

Analysis of the several aspects of medication prescription by nurses in Brazil and in Ontario brings about an opportunity to learn about the different social practices regarding this matter and, within this scope, extrapolate territorial limits to add new ways of performing medication prescription by nurses as a necessary service for people's health, providing access and consolidating comprehensiveness. Even though Brazilian and Canadian nurses have different models of prescription, there still are many challenges to overcome, such as: guarantee of professional competence, credibility, acceptability, and respectability of the clientele of your professional scope by other health professionals. These issues are particularly conquered by the professional nurse based on their own self-worth, which is realized from the assumption of their ethical commitment and joint responsibility of their healthcare practice. 
Congestion of health services is common to both contexts studied in this present work, and thus innovations and strategies to reduce the weaknesses in health care are necessary. The need for nurses to base their prescribing practice on sound pharmacological knowledge has been highlighted, however nurses' need for further multidimensional training. As independent prescribing is extended to cover nurses working across a range of different settings, and as other groups of nurses and professionals begin supplementary prescribing in the near future, further research is required to enable more definitive conclusions about the effectiveness of this expanding reality.

\section{Acknowledgments}

To Nurses Krista Keilty (Pediatric Nurse Practitioner), Monica Parry (Nurse Practitioner in Primary Health Care), Janelice de Azevedo Neves Bastiani (Primary Health Care Nurse) and Teresa Cristina Gaio da Silva (Public Health Nurse) for their outstanding contribution to this work.

\section{References}

1. Fairmann J. Making room in the clinic: Nurse practitioner and the evolution of modern health care. 5.ed. New Jersey: Rutgers University; 2008.389 p.

2. Ximenes FRG, Costa FAM, Chagas MIO, Cunha ICK. Olhares dos enfermeiros acerca de seu processo de trabalho na prescrição medicamentos na Estratégia Saúde da Família. Rev Bras Enferm. 2007;60(2):13340.

3. Lei n. 179 de 29 de setembro de 2009 (CN). Dispõe sobre o Committee Transcripts: Standing Committee on Social Policy and Regulated Health Professions Statute Law Amendment Act [Internet]. Legislative Assembly of Ontario; 2009. [Acesso 26 mar 2012]. Disponível em: http://www.ontla.on.ca/web/committeeproceedings/ committee_transcripts_details.do?locale $=$ fr\&Date $=200$ 90929\&ParlCommID $=8875 \&$ BillID $=2189 \&$ Business $=\& D$ ocumentID $=24349$.

4. Decreto-lei no $94.406 / 87$ de 08 de junho de 1987 (BR). Regulamenta a Lei 7498/86 sobre o Exercício da Enfermagem e dá outras providências. Diário Oficial República Federativa do Brasil. Brasília (DF); jun 1987. p. 8853-5.

5. Ministério da Saúde (BR). Saúde da Família: uma estratégia para a reorientação do modelo assistencial. Brasília (DF): Ministério da Saúde; 1997.
6. Parecer Técnico COREN/SC No 003/CT/2010 (BR). Dispõe sobre a prescrição de plantas medicinais e fitoterápicos [Internet]. Curitiba: Conselho Regional de Enfermagem de Santa Catarina; 2010. [Acesso 10 mai 2012]. Disponível em: http://www.corensc. gov.br/documentacao2/CT_Prescricao_de_Plantas_ Medicinais_e_Fitoterapicos.pdf.

7. Ministério da Saúde (BR). Política Nacional de Atenção Básica, diretrizes e normas para a organização da Atenção Básica, para a Estratégia Saúde da Família (ESF) e Programa de Agentes Comunitários de Saúde. Brasília (DF): Ministério da Saúde; 2010.

8. McDougall H. Health Canada. Making Medicare: The History of Health Care in Canada, 1914-2007. Waterloo: Wilfrid Laurier University; 2010.105 p.

9. Hutchison B. A Long Time Coming: Primary Healthcare Renewal in Canada. Healthc Pap. 2008;8(2):10-24.

10. Donald F, Martin-Misener R, Bryant-Lukosius D, Kilpatrick K, Kaasalainen S, Carter N, et al. The primary healthcare nurse practitioner role in Canada. Nurs Leadership. 2010;23(Spec issue):88-113.

11. McPherson KM. Bedside Matters: the transformation of Canadian nursing, 1900-1990. Toronto: Oxford University Press;1996.175 p.

12. Ata n. $91 / 18$ de 6 de novembro de 1991 (CN). Regulated Health Professions Act [Internet]. Toronto. Legislative Assembly of Ontario; 1991. [Acesso $31 \mathrm{dez}$ 2012]. Disponível em: http://www.elaws.gov.on.ca/ html/statutes/english/elaws_statutes_91r18_e.htm.

13. Nurse Association of Ontario. Managing Disruptive Physician Behaviour. Canada: Ontario Nurses' Association (ONA);2010. http://www.ona.org/documents/ File/guides/Guide_ManagingDisruptivePhysicianBehaviour_201006.pdf (accessed April 6, 2012).

14. College of Nurses of Ontario. Practice Standard: Nurse Practitioner. Ontario; 2011. 25 p.

15. Oguisso T, Freitas GF. Enfermeiros prescrevendo medicamentos: possibilidades e perspectivas. Rev Bras Enferm. [Internet]. abr 2007 [Acesso 2 ago 2014];60(2):141-4.

16. French SE, Emed JD. Nursing and globalization in the Americas: A critical perspective. New York: Baywood Publishing; 2009. 274 p.

17. Ata n. 09026 de 15 de dezembro de 2009 (CN). An Act to amend various Acts related to regulated health professions and certain other Acts [Internet]. Ontario: Service of Ontario; 2009. [Acesso 20 jun 2012]. Disponível em: http://www.elaws.gov.on.ca/ html/source/statutes/english/2009/elaws_src_ s09026_e.htm 
18. Ministério da Saúde (BR). Política Nacional de Promoção da Saúde. Brasília (DF): Ministério da Saúde; 2006.

19. Ceolin T, Heck RM, Pereira DB, Martins AR, Coimbra VCC, Silveira DSS. A inserção das terapias complementares no sistema único de saúde visando o cuidado integral na assistência. Enferm Global. [Internet] 2009. [Acesso 20 jun 2012];16. Disponível em: 